\title{
A resilient scheme for a flexible smart grid using Transformation optimization towards sustainable energy
}

\author{
D. Vijayakumar ${ }^{1}$ S. Gopalakrishnan ${ }^{2}$ \\ ${ }^{1}$ Associate Professor, Department of Electronics and Communication Engineering, CMR College of Engineering \& Technology, \\ Kandlakoya, Medchal Road, Hyderabad, India, vkkumarin@gmail.com \\ ${ }^{2}$ Assistant Professor, Department of Electronics and Communication Engineering, CMR College of Engineering \& Technology, \\ Kandlakoya, Medchal Road, Hyderabad, India.
}

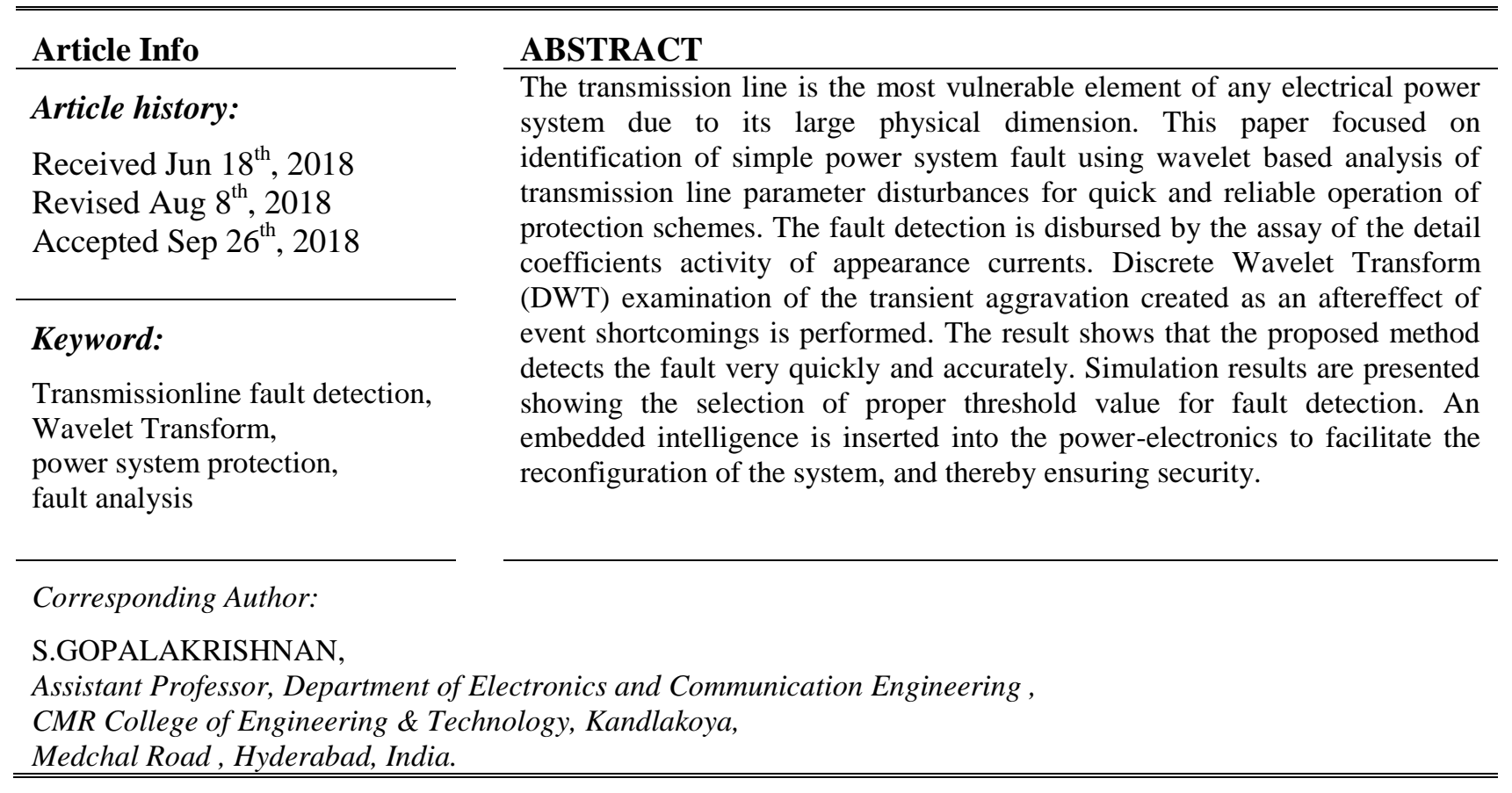

\section{Introduction}

The Smart Grid is an evolution of the electrical grid to a flexible power network through distributed intelligence, automated control systems, and communication technologies. The electric power transmission network has been dynamically created in excess of one century, from the initial designed local DC network in low voltage level, to three-phase high voltage AC network, and to present day mass interconnected systems with different voltage levels and bounty of complex electrical components. The power management techniques must yield sustainable energy; although there is increasing power blackouts due to the excessive power consumption. The demerits in the existing power grid models occur at the system level and local level. The control area operators in the power grid cannot, obtain the real-time information about the transmission devices, respond quickly to emergency events (or) blackouts, and perform the functions in an automated and coordinated manner.

The conventional hardware used in the electrical grid lacks the frequency and voltage control according to the increasing system requirements, and cannot secure the system quickly during emergency events. A realtime coordination scheme enhances the coordination among the geographically separated devices during power blackouts. The energy resources in the transmission systems must be efficiently utilized over the conventional high-energy resources to increase the reliability of the power system. The security of a power grid is mainly focused on dynamic and transient stability issues. The attacks on the power grids may partially compromise the secure communication or fully control some of the system components. 
Transmission lines presented to different deficiencies are outlined with distance protection scheme. The computation of line impedance has been done in contrast mathematical statements [1],[2] or utilizing phasor got by Fourier calculations [3],[4].Wavelet analysis as a capable tool for signal transforming can be connected to adequately overcome troubles of the travelling wave protection procedures. The execution time of the resource scheduling is decreased by the optimization of wavelet analysis. This method performs better than the existing power grid models in terms of fault detection, degree of power saving due to power optimization, memory usage, consumer computational overhead, and critical time. The existing methods taken for comparative analysis are Fault detection and classification using Efficient and Privacy-Preserving Aggregation (EPPA) scheme, Lightweight Message Authentication (LMA) scheme, Multi-terminal DC Wind farm collection Internal Fault Analysis (MDWIFA), and traditional scheme (TRAD) without any data aggregation.

\section{Related work}

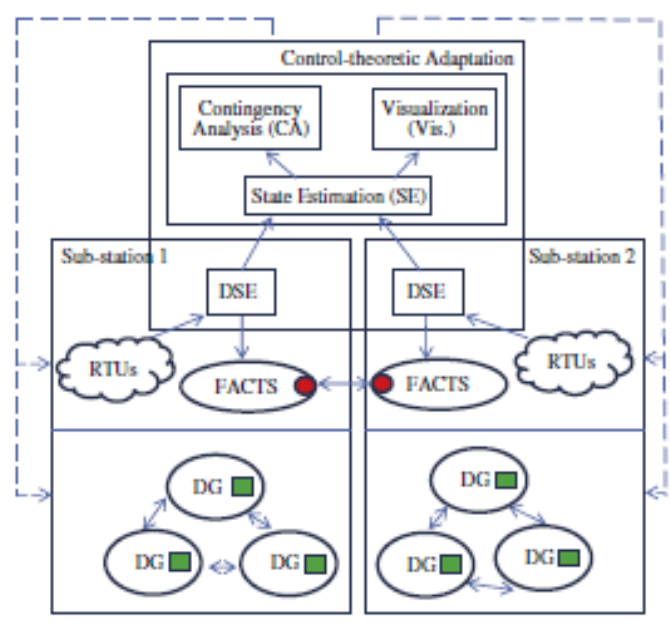

This section deals with the existing secure and optimized power grid models. Also basics of fast detecting, isolating, locating and repairing of the different faults are critical in maintaining a reliable power system operation [5]. On the other hand, classification of the different fault types plays very important role in digital distance protection of the transmission lines [6]. A smart grid is a modern electrical grid infrastructure for higher efficiency and reliability via automated control, modern communications, sensing, high power converters, metering technologies, and energy management schemes [7]. The recent smart grid management and protection systems were surveyed by [8] and [9]. The suitability of Attribute Based Encryption (ABE) was analyzed for the security of smart grids [10].Miao and Junshan proposed a dependency graph based fault detection and localization towards secure smart grid [11].Fouda, et al designed a lightweight message authentication technique for smart grids [12]. The smart meters were distributed at various hierarchical smart grid networks. Young-Jin, et al formed a data-centric, decentralized and secure information infrastructure for smart grid [13]. The secure middleware architecture can coexist with both LAN and WAN. Rodri, et al used a grid synchronization algorithm for three-phase grid-connected power networks [14].Chouder and Silvestre implemented automatic and supervisory fault detection technique on the Photo-Voltaic (PV) systems of the smart grid [15]. Vijayakumar et al have proposed an enhanced ACO and PSO based fault identification and rectification approaches for smart gird. In this approach, the smart grid configuration is not discussed[16].Huimin, et al designed a protection scheme for smart MVDC (MediumVoltage DC) grid[17].

Rongxing, et al proposed an efficient and privacy-preserving aggregation methodology for securing the smart grid communications [18]. Calderaro, et al detected and localized the failures in smart grids using petri net (PN) modeling [19]. The detection of faults was modeled as matrix operations. This method enabled the 
fault identification the strong effect of distributed generation. Chanda et al. [20] have proposed an algorithm with Daubechies eight (Db8) wavelet for fault classification in transmission line using 3rd level output of multi-resolution analysis (MRA) detail signals of currents. But in that algorithm the phases involved in the fault does not explicitly determined and time duration considered in the analysis comes out to $40.96 \mathrm{~ms}$, which is about two cycles after post fault. Recently, Upendar et al. [21] have presented an algorithm based on the wavelet transform of three phase currents and the PNN and the classification and regression tree (CART) methods. The accuracy of the fault classification method has been reported over 99\% upon 1,209,960 test cases. Also, the fault identification algorithm is low speed. Vijayakumar et al [22] have proposed a real time management and evolutionary optimization scheme for a secure and flexible smart grid through a modern configuration environment. In this approach, smart grid infrastructure is made it easy and power overheads are introduced.

\section{Real Time Management And Transformation Scheme For A Flexible Smart Grid (RMTSFS)}

A resilient and reconfigurable electrical grid is designed using fault-tolerant real-time controls to handle Instantaneous and intentional attacks in the grid. The power grid is integrated with centralized system-level adaptation and embedded intelligence based load actuation to form an efficient smart grid.

\subsection{Hybrid architecture for distribution control}

A distributed control mechanism is considered, where the distributed controllers communicate the information with the primary peers to guarantee the reliability and safety of local operations. Distributed control is required because the higher distributed power generation, transmission, and distribution necessitates the distributed command and control. The hybrid architecture is shown in Fig.1. The embedded controllers are shown in filled circles and squares.

This hybrid architecture supports distributed control which differs from the conventional power grid in the following perspectives:

- The generator and transmission devices are integrated with a controller to make executions based on collaborative information.

- The collaboration levels at generator and transmission sides prevent isolated and coordinated attacks.

- A distributed state estimator (DSE) is used at each substation to decrease SE execution time and furnish the feedback on local faults.

\subsection{Enhancing Security through reconfiguration of system}

The power grid is transformed into a reconfigurable grid by the incorporation of power electronic devices with control and sensing functions. Reactive power control and management is necessary for efficient voltage control/stability. The aim of intelligent controllers is to determine the quantity of real and reactive power to the employed in the grid under specific variations in detection of current, frequency, or voltage.

The power grid is partitioned into several microgrids containing generators and loads separated from the primary grid. The microgrids can provide power at least to sensitive loads during contingency and system attacks. Normally, the generators operate in a current control mode where they are tightly synchronized with the primary grid. But, when there is power failure due to component attacks or the microgrid is disconnected from the primary grid, the generators need to transform to voltage control mode for providing constant voltage to at least the local sensitive loads. The need for an intelligent load shedding scheme relies on the determination of local voltage and frequency transients for each generator.Consider a microgrid with three 
generators and four sensitive loads. The total quantity of active and reactive power required by the load is given in (1) and (2) respectively.

$$
\begin{aligned}
& \sum \mathrm{P}_{\mathrm{L}}=\mathrm{P}_{\mathrm{L}_{1}}+\mathrm{P}_{\mathrm{L}_{2}}+\mathrm{P}_{\mathrm{L}_{3}}+\mathrm{P}_{\mathrm{L}_{4}} \\
& \sum \mathrm{Q}_{\mathrm{L}}=\mathrm{Q}_{\mathrm{L}_{1}}+\mathrm{Q}_{\mathrm{L}_{2}}+\mathrm{Q}_{\mathrm{L}_{3}}+\mathrm{Q}_{\mathrm{L}_{4}}
\end{aligned}
$$

The total quantity of active and reactive power released by the generators is given in (3) and (4) respectively.

$$
\begin{aligned}
& \sum \mathrm{P}_{\mathrm{G}}=\mathrm{P}_{\mathrm{G}_{1}}+\mathrm{P}_{\mathrm{G}_{2}}+\mathrm{P}_{\mathrm{G}_{3}} \\
& \sum \mathrm{Q}_{\mathrm{G}}=\mathrm{Q}_{\mathrm{G}_{1}}+\mathrm{Q}_{\mathrm{G}_{2}}+\mathrm{Q}_{\mathrm{G}_{3}}
\end{aligned}
$$

The micro grid operates constantly even after power failure by balancing the conditions given in (5).

$$
\sum \mathrm{P}_{\mathrm{L}}=\sum \mathrm{P}_{\mathrm{G}} ; \quad \sum \mathrm{Q}_{\mathrm{L}}=\sum \mathrm{Q}_{\mathrm{G}}
$$

The normal range for the operation of microgrids according to IEEE Std. $1547 \mathrm{is} 0.88 \mathrm{pu}-1.1 \mathrm{pu}$. The switching of the generator inverter system to voltage control mode is a major issue. When the speed of voltage variation is detected once the facility failure, the number of load shedding or reduction in generation is determined before switch to voltage control mode. The local frequency and voltage is monitored to accelerate the responsiveness to changes within the system state. The controllers within the multiple generators crash as a result of there's no info exchange between the generators, that doesn't accurately estimate the state of the microgrid. This problem is issued by the following alliance algorithm.

\subsection{Alliance algorithm}

When a controller is integrated with a power electronic device, the communication links to the controllers from the field remote terminal units (RTUs) can be damaged. This results in loss of data or false data. The local controllers need to execute correct decisions that do not affect the grid reliability or stability. A distributed interval integration algorithm [23] is used, where the generator is chosen to collect the device output and develop an overlap function. The significance of this algorithm is the decreased width of the output interval for a case of a large number of devices. The following conditions are considered to determine the alliance of the local controller with its neighbors:

1) The overlap function possesses its maximum values from $\left[s_{n}-f_{i}, s_{n}\right]$, where $s_{n}$ represents the total number of sensors and $i$ represents the total number of faulty device inputs.

2) The mid-value of the integration has to be equal to or greater than the median of the estimated interval.

3) Both the conditions 1) and 2) have to be fulfilled in two consecutive integrations excluding the first round so that decision stability is enhanced. 


\subsection{Reactive power management and scheduling}

An important want for an influence grid system is that the ability to security attacks and unpredictable variations. A control-theoretic module is employed to realize the dynamicity to quality-of-service (QoS) attacks. The facility grid system is sculptured as controlled variables primarily based dynamic system. The QoS attributes like time period time interval and output ought to monitor the QoS specifications. once disturbances occur as a result of the QoS attacks, the devices could get broken as a result of abnormal voltage, current, or frequency. A real-time scheduling algorithm is designed based on control theory for scheduling the energy resources in the grid and assuring the end-to-end real-time constraints. The goal of the short-term energy resource management is to minimize the operational costs.

The reactive power management process is sculpted as a constrained, large-scale, mixed, non-linear, and optimization problem as depicted in (6) and (7).

$$
\begin{aligned}
& \min _{a \in \mathbb{R}^{n_{s}}} p(a, b) \\
& \text { s.t. }\left\{\begin{array}{l}
m(a, b)=0 \\
n(a, b) \leq 0
\end{array}\right.
\end{aligned}
$$

In (6) and (7), p(a,b) represents the objective function, $\mathrm{m}(\mathrm{a}, \mathrm{b})$ consists of the equality constraints, and $n(a, b)$ consists of the inequality constraints.

\subsection{Mathematical model}

The primary factor for voltage instability is the inefficiency in the maintenance of an appropriate voltage level and reactive power management. The energy resource scheduling is modeled according to the following mathematical model identified as a non-linear mixed-integer problem. The objective function $f(s, c)$ in $(8)$ is formulated to determine the minimum operational costs in each period t. The constraint for consideration is given in (9).

$$
\begin{array}{cc}
\min f(s, c)=\min \left[\sum_{\mathrm{T}_{1}=1}^{\mathrm{n}_{\mathrm{T}_{1}}} \mathrm{P}_{\mathrm{E}_{1}\left(\mathrm{~T}_{1}, \mathrm{t}\right) \cdot \mathrm{g}_{\mathrm{E}_{1}\left(\mathrm{~T}_{1}, \mathrm{t}\right)}+}\right. & \sum_{\mathrm{T}_{2}=1}^{\mathrm{n}_{\mathrm{T}_{2}}} \mathrm{P}_{\mathrm{E}_{2}\left(\mathrm{~T}_{2}, \mathrm{t}\right) \cdot \mathrm{g}_{\mathrm{E}_{2}\left(\mathrm{~T}_{2}, \mathrm{t}\right)}+\cdots+} \\
\left.\sum_{\mathrm{T}_{\mathrm{m}}=1}^{\mathrm{n}_{\mathrm{T}_{\mathrm{m}}}} \mathrm{P}_{\mathrm{E}_{\mathrm{m}}\left(\mathrm{T}_{\mathrm{m}}, \mathrm{t}\right)} \cdot \mathrm{g}_{\mathrm{E}_{\mathrm{m}}\left(\mathrm{T}_{\mathrm{m}}, \mathrm{t}\right)}\right] \quad \forall \mathrm{t} \in\{1, \ldots, \mathrm{T}\} &
\end{array}
$$

In (8), $m$ represents the number of energy resources, $E_{1}, E_{2} \ldots E_{m}$ represents the various energy resources, $\mathrm{T}_{1}, \mathrm{~T}_{2} \ldots \mathrm{T}_{\mathrm{m}}$ represents the unit energy value of various energy resources, $\mathrm{n}_{\mathrm{T}_{1}}$ represents the number of type-1 resources, $\mathrm{n}_{\mathrm{T}_{2}}$ represents the number of type- 2 resources, $\mathrm{n}_{\mathrm{T}_{\mathrm{m}}}$ represents the number of type-m resources, $\mathrm{P}$ represents the active power generation and $\mathrm{g}$ represents the generation cost. The power in (8) must be balanced in each period t.

$$
\begin{aligned}
& \sum_{\mathrm{T}_{1}=1}^{\mathrm{n}_{\mathrm{T}_{1}}} \mathrm{P}_{\mathrm{E}_{1}\left(\mathrm{~T}_{1}, \mathrm{t}\right)} \cdot \mathrm{g}_{\mathrm{E}_{1}\left(\mathrm{~T}_{1}, \mathrm{t}\right)}+\quad \sum_{\mathrm{T}_{2}=1}^{\mathrm{n}_{\mathrm{T}_{2}}} \mathrm{P}_{\mathrm{E}_{2}\left(\mathrm{~T}_{2}, \mathrm{t}\right)} \cdot \mathrm{g}_{\mathrm{E}_{2}\left(\mathrm{~T}_{2}, \mathrm{t}\right)}+\ldots \ldots+\quad \sum_{\mathrm{T}_{\mathrm{m}}=1}^{\mathrm{n}_{\mathrm{T}_{\mathrm{m}}}} \mathrm{P}_{\mathrm{E}_{\mathrm{m}}\left(\mathrm{T}_{\mathrm{m}}, \mathrm{t}\right)} \cdot \mathrm{g}_{\mathrm{E}_{\mathrm{m}}\left(\mathrm{T}_{\mathrm{m}}, \mathrm{t}\right)}= \\
& \sum_{\mathrm{L}=1}^{\mathrm{n}_{\mathrm{L}}} \operatorname{Load}_{(\mathrm{L}, \mathrm{t})}+\quad \mathrm{P}_{\text {loss }} \quad \forall \mathrm{t} \in \\
& \{1, \ldots, \mathrm{T}\}
\end{aligned}
$$

In (9), $\operatorname{Load}_{(\mathrm{L}, \mathrm{t})}$ represents the active power requirement of load $\mathrm{L}$ in period $\mathrm{t}$ and $\mathrm{P}_{\text {loss }}$ represents the total power losses in the distribution lines which is the $5 \%$ value of the former parameter. $\mathrm{n}_{\mathrm{L}}$ represents the number of loads. 


\section{Wavelet Transforms for Fault Analysis}

\subsection{Wavelet transformation and entropy calculation}

Lots of fault info is enclosed within the transient parts. Thus it will be accustomed determine the fault or abnormality of equipments or power grid. This fashion the dependableness of the facility system are going to be significantly improved. Transient signals have some characteristics like high frequency and instant break. The wavelet decomposition and entropy calculations are done on each phase to identify the faults in each phase and presence of ground fault can be identified based on the wavelet transform and entropy calculation on zero sequence currents. A frequency-independent real transformation matrix will be accustomed acquire somewhat decoupled signals which will be advantageous in transient primarily based fault detection.

\subsection{Extraction of Transient Energy Using Wavelet Transform}

The simulated transient signals are obtained from high voltage transmission line Simulink model and are analyzed for various conditions of single line to ground fault. Using wavelet multi resolution analysis the detail components at level 1 and level 3 have been taken into account. A moving data window of one cycle width has been taken for analysis. The fault signals are discretized for analysis and so they are called discrete time signals. The sampling frequency is $320 \mathrm{kHz}$, thus one data window contains 6400 samples. A $220 \mathrm{kV}$ power system is simulated using MATLAB ${ }^{\circledR} /$ Simulink, Sim Power System toolbox, wavelet toolbox and neural network toolbox for different fault conditions on the line. The details of power system model are as given in Table-1. The line voltage signals from both the ends of are used for fault analysis on the transmission line. Daubechies „db3 $3^{\text {ee }}$ wavelet is employed since it has been demonstrated to perform well. The details of the Wavelet and associated parameters are given in Table -2. Using multi resolution wavelet analysis of all the voltage signals their detail D1 and D3 components are extracted. The third level detail D3 contains harmonics ranging from $5 \mathrm{kHz}-10 \mathrm{kHz}$ and the first level detail D1 contains harmonics ranging from $80 \mathrm{kHz}-160 \mathrm{kHz}$. It has been observed that variations within the detail information of the voltage signal contains useful fault signature. All the single line to ground faults were studied with different fault conditions. Fault is simulated to appear in second cycle.

Table 1 Parameters of the power system

\begin{tabular}{|c|l|}
\hline Generator 1 & $\begin{array}{l}\text { 220Kv,Y-gX/R=10, } \\
\text { Phase Angle=0 }\end{array}$ \\
\hline Generator 2 & $\begin{array}{l}\text { 220Kv,Y-gX/R=10, } \\
\text { Phase Angle=75 }\end{array}$ \\
\hline Load 1 & 20 kW Active, 900 W Reactive \\
\hline Load 2 & $\begin{array}{l}\text { Re kW Active, 900 W } \\
\text { Reactive }\end{array}$ \\
\hline \multirow{3}{*}{$\begin{array}{c}\text { Transmission line } \\
\text { (Distributed) }\end{array}$} & $\begin{array}{l}\text { Length }=200 \mathrm{~km} \\
\mathrm{R}=0.01273 \mathrm{ohms} / \mathrm{km}, \\
\mathrm{Ro}=0.3864 \mathrm{ohms} / \mathrm{km}\end{array}$ \\
& $\begin{array}{l}\mathrm{Lo}=4.9337 \mathrm{e}-3 \mathrm{H} / \mathrm{M}, \\
\mathrm{C}=12.74 \mathrm{e}-9 \mathrm{e} / \mathrm{km} / \mathrm{km}\end{array}$ \\
& $\mathrm{Co}=7.751 \mathrm{e}-9 \mathrm{~F} / \mathrm{km}$ \\
\hline
\end{tabular}

Table 2 Details of wavelet and associated parameters 


\begin{tabular}{|c|l|}
\hline Mother wavelet & Doubechies, db3 \\
\hline $\begin{array}{c}\text { Sampling } \\
\text { Frequency }\end{array}$ & $320 \mathrm{kHz}$ \\
\hline $\begin{array}{c}\text { Information } \\
\text { analyyzed }\end{array}$ & $\begin{array}{l}\text { Detail at level 3 and level 1, } \\
\text { D3, D1 }\end{array}$ \\
\hline $\begin{array}{c}\text { Frequency band of } \\
\text { D3 }\end{array}$ & $5 \mathrm{kHz}-10 \mathrm{kHz}$ \\
\hline $\begin{array}{c}\text { Frequency band of } \\
\text { D1 }\end{array}$ & $160 \mathrm{kHz}-80 \mathrm{kHz}$ \\
\hline $\begin{array}{c}\text { Number of samples } \\
\text { per cycle }\end{array}$ & 6400 \\
\hline Occurrence of fault & Second cycle \\
\hline $\begin{array}{c}\text { Data windoe length } \\
\text { analysed }\end{array}$ & One cycle/20msec \\
\hline
\end{tabular}

The transient energy is calculated for first three data window and were used for further analysis. The simulation results of Wavelet transformation for the detection of three phase faults. The three phase fault is occurred for the duration of time 0.02 to $0.08 \mathrm{~s}$. The measured and saved values of the line currents were exported in MATLAB for further data processing.

The simulation results obtained using $\mathrm{db} 3$ analysis of wavelet transformations are shown in figure.3. In that figure, red colored line indicates the threshold limit, which is obtained by comparing the wavelet packets.

After threshold has been identified, a final step for the detection algorithm is to calculate their repetition rate. Based on the repetition rate, a step waveform is obtained and the final settling step value is the fault detection time $0.154 \mathrm{~s}$ and it is shown in figure. 4

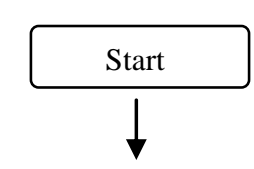

Discrete Wdvelet Tonl 
Component Filtering of both voltages and current

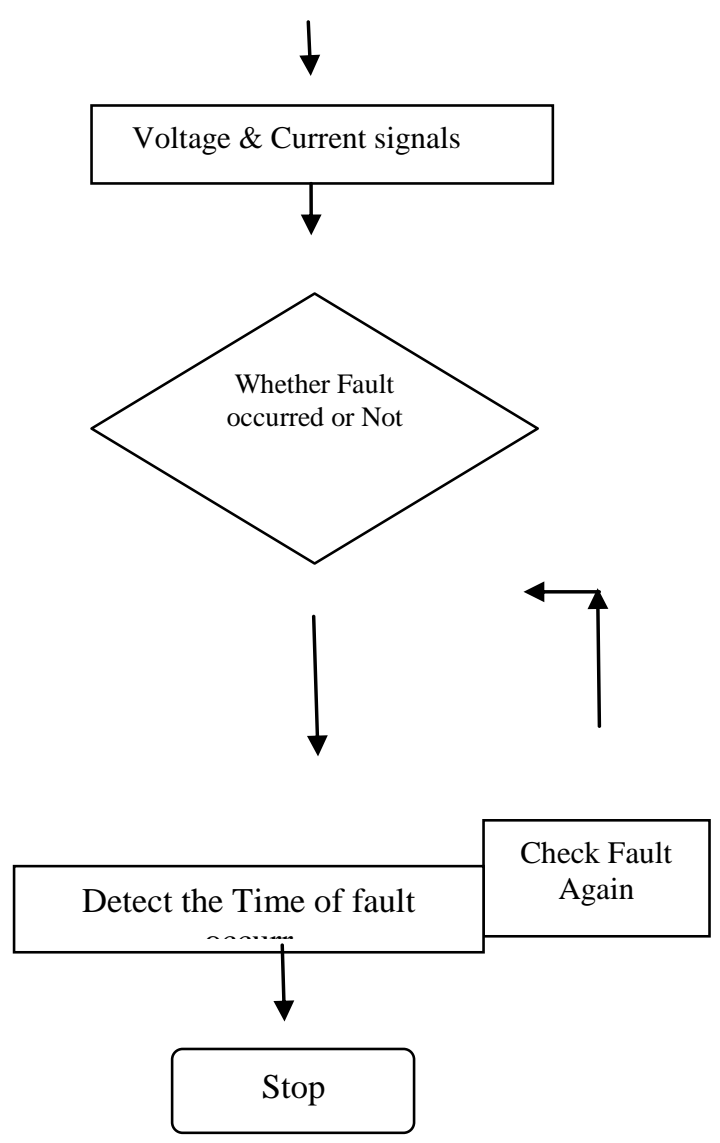

Figure 2 Optimization process based on wavelet

\section{$5 \quad$ Performance Analysis}

The real-time management and transformation scheme for a flexible smart grid (RMTSFS) towards sustainable energy is analyzed in terms of fault detection, memory usage, consumer computational overhead, and critical time. The voltage of the transmission line is considered as $35 \mathrm{kV}$. The existing methods considered for comparative analysis are Fault detection and classification using Efficient and Privacy-Preserving Aggregation (EPPA) scheme[18], Lightweight Message Authentication (LMA) scheme[12], Multi-terminal DC Wind farm collection Internal Fault Analysis (MDWIFA)[25], and traditional scheme (TRAD) without any data aggregation[24]. 


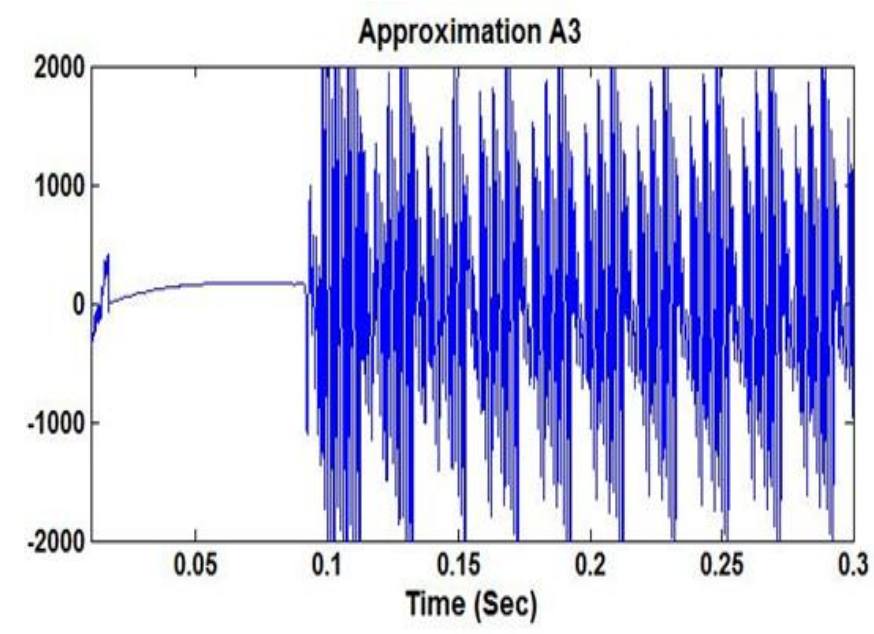

Detail D2

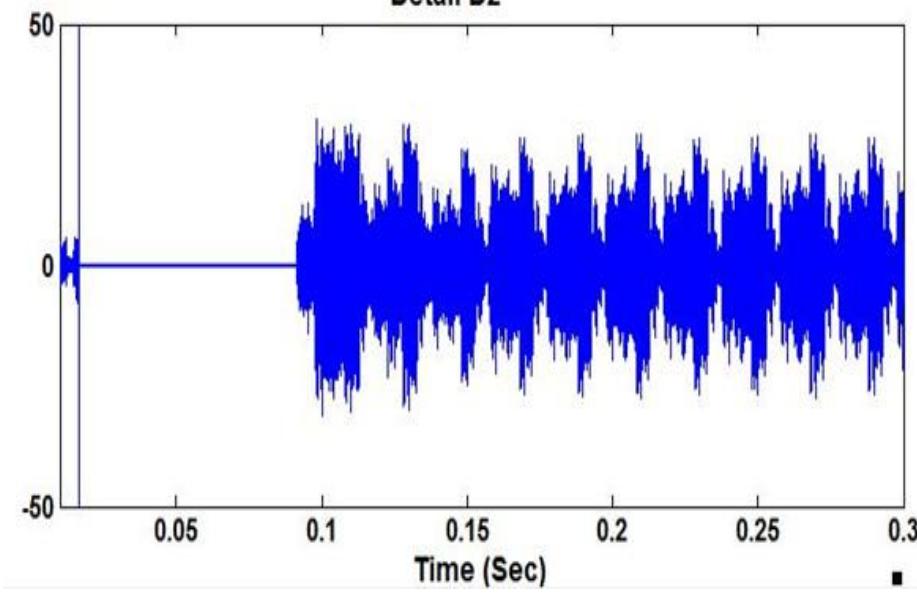

Detail D1

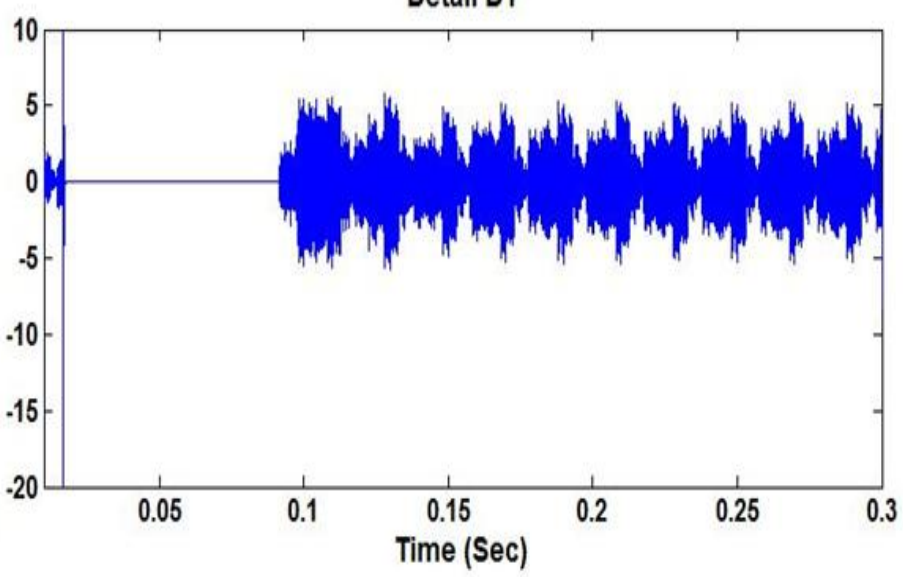

Detail D3

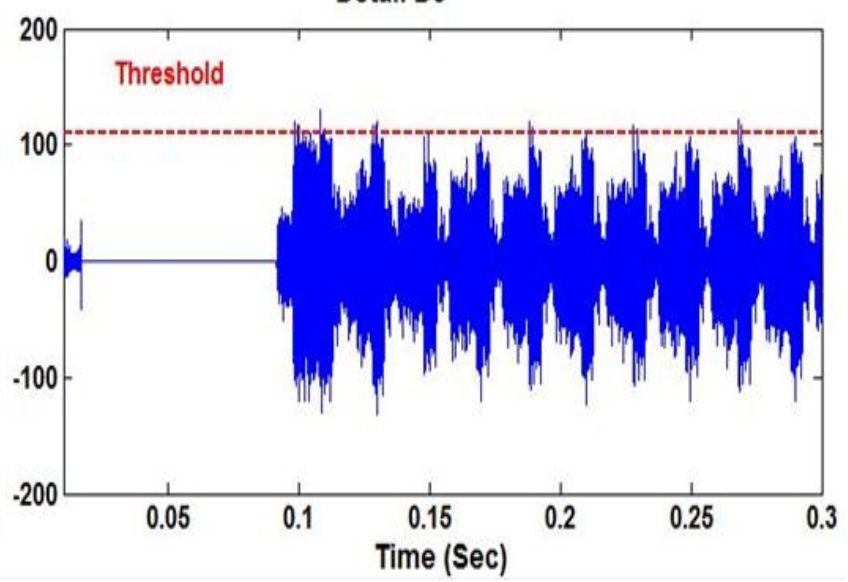

Figure 3 Occurrence of fault in the transmission line the gap between the waveform(0.02-0.08s)is depicted as fault

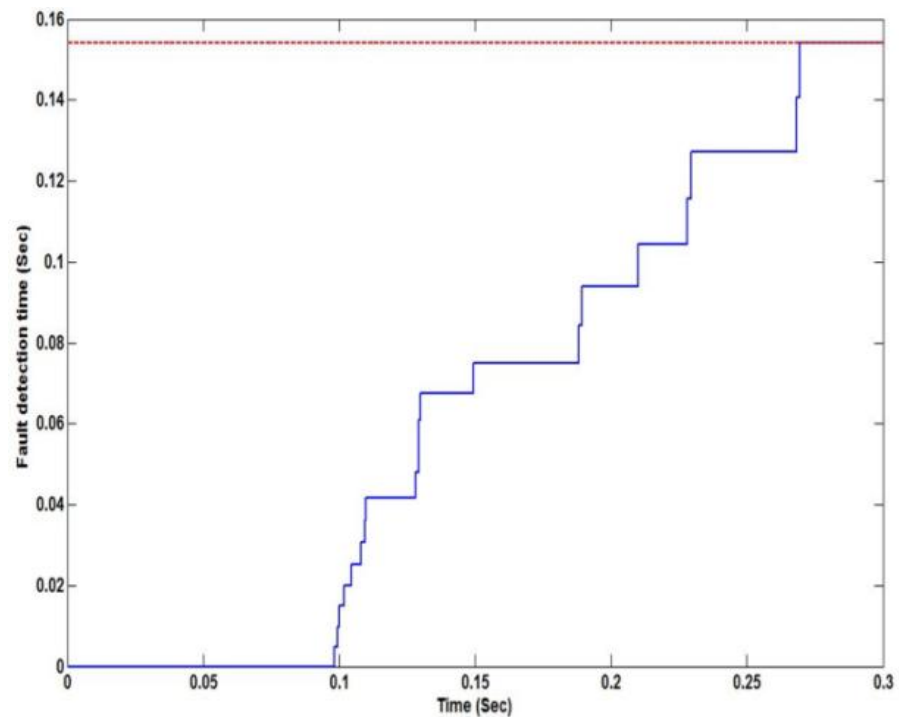

Figure 4. Fault Detection Time for RMTSFS

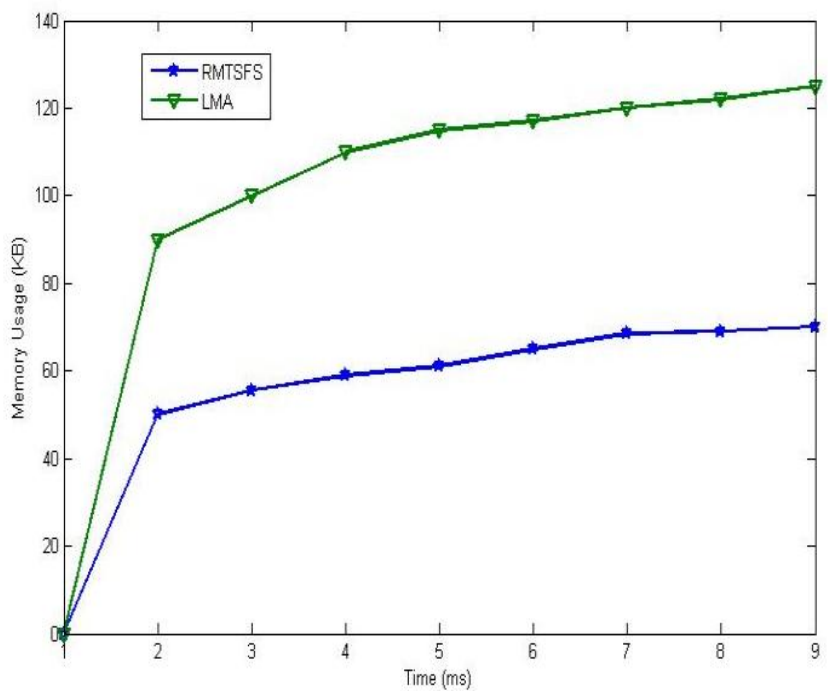

Figure 5. Memory usage of LMA and RMTSFS 


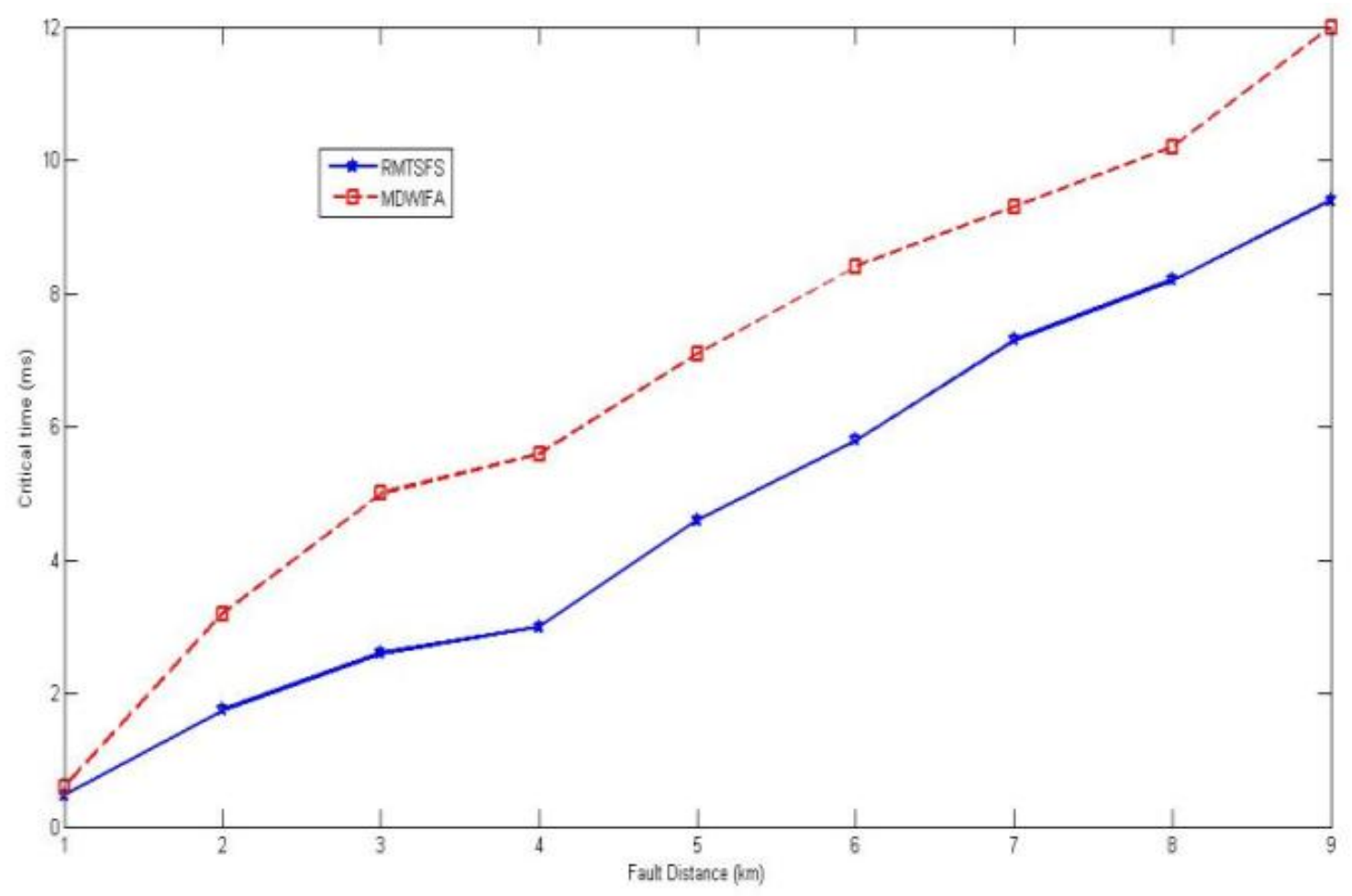

Figure 6. Consumer computational overhead of EPPA, TRAD and RMTSFS

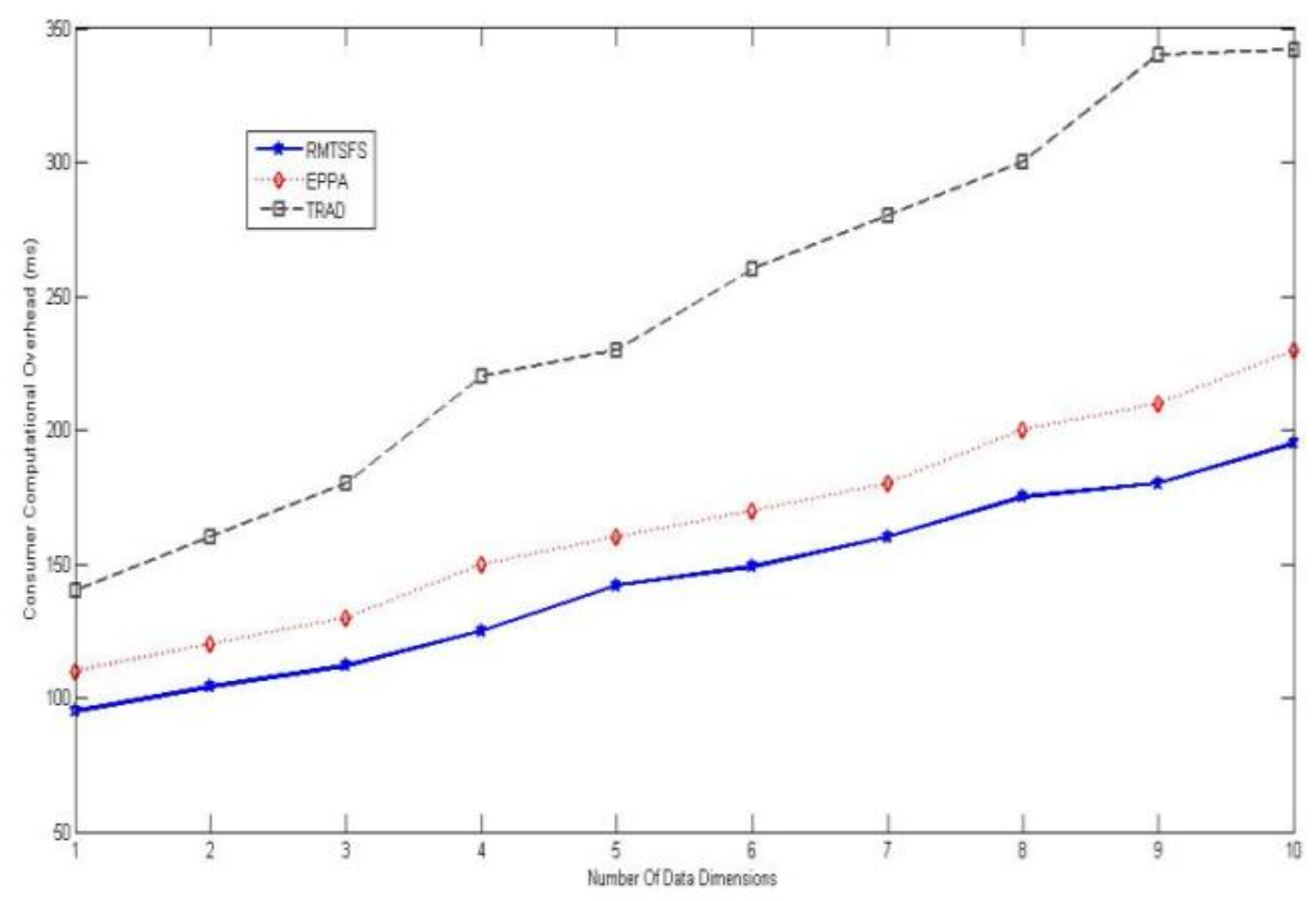

Figure 7. Critical time of MDWIFA and RMTSFS 


\subsection{Fault detection}

The occurrence and detection of fault in the transmission is shown in Fig.4. The X-axis represents time in seconds and the $\mathrm{Y}$-axis represents the amplitude of voltage $(\mathrm{mV})$ and current $(\mathrm{mA})$. The blue colored waveform represents the fault reference line. The gap between the waveforms $(0.02 \mathrm{~s}-0.08 \mathrm{~s})$ is depicted as a fault. The fault detection time is analysed by RMTSFS and detect the fault instantly as around $\mathrm{t}=0.15 \mathrm{~s}$.

\section{$5.2 \quad$ Memory usage}

The memory usage of LMA scheme and RMTSFS is analyzed and compared with respect to time in Fig.5. It is observed that RMTSFS consumes lesser memory than LMA scheme.

\subsection{Consumer computational overhead}

The consumer computational overhead of EPPA scheme, TRAD scheme and RMTSFS is analyzed and compared with respect to the number of data dimensions in Fig.6. It is observed that RMTSFS consumes lesser overhead in terms of computations than EPPA and TRAD schemes.

\subsection{Influence of fault distance on critical time}

Critical time is the limit for the total switchgear operation time. It should be small for the faster operation of the power grid. The critical time for MDWIFA and RMTSFS is analyzed and compared with respect to fault distance in Fig.7. It is seen that RMTSFS performs the switchgear operations even when the faults are detected increasing distances from the control center.

\section{Conclusion}

Sustainable energy is very important for the future energy generation and management technologies. A real-time management and transformation scheme for a flexible smart grid towards sustainable energy is designed in this paper. The existing power grid models cannot obtain the real-time information about the transmission devices, perform the functions in an automated and coordinated manner, and respond quickly to emergency events (or) blackouts. This method consists of a location hybrid architecture following a alliance algorithm to address the faulty and incomplete information. The system reconfiguration via power-electronics and switches is used for the real-time accessibility control, local state maintenance, and security enhancement. An wavelet transformation is used to address the reactive power management and optimum transmission device placement. The execution time of the resource scheduling is decreased by the optimization of wavelet transformation. This technique performs better than the existing power grid models in terms of fault detection, memory usage, consumer computational overhead, and critical time.

The future work consists of real-time implementation using hardware toolkits to verify the practical energy consumption and optimization performance.

\section{References}

[1] G. B. Gilcrest, G. D. Rockefeller, and E. A. Udren, "High speed distance relaying using a digital computer, part 1-System description,” IEEE Trans. Power App. Syst., vol. PAS-91, no. 3, pp. 12351243, 1972.

[2] B. J. Mann and I. F. Morrison, "Digital calculation of impedance for transmission line protection," IEEE Trans. Power App. Syst., vol. PAS-90, no. 1, pp. 270-278, 1971.

[3] D. L. Waikar, S. Elangovan, and A. C. Liew, "Fault Impedance Estimation Algorithm for Digital Distance Relaying,” IEEE Trans. Power Delivery, vol. 9, no. 3, pp. 1375-1383, Jul.1994. 
[4] Z. Y. Xu, "An ultra-high speed distance protection algorithm," in Proc. IEEE and CSEE Int. Conf. Power System Technology, Beijing, China, Oct. 1994, pp. 1149-1152.

[5] Elhaffar A. M., Power transmission line fault location based on current traveling waves, Helsinki university of technology 2008.

[6] Phadke A. G., Computer relaying for power systems, John Wiley \& Sons Ltd., New York 1988.

[7] Gungor VC et al. Smart grid technologies: communication technologies and standards. Ind Inf, IEEE Trans 2011;7:529-39.

[8] Xu L et al. Securing smart grid: cyber attacks, countermeasures, and challenges. Commun Mag, IEEE 2012;50:38-45.

[9] Sridhar S et al. Cyber-physical system security for the electric power grid. Proc IEEE 2012;100:210-24.

[10] Fadlullah ZM et al. Toward secure targeted broadcast in smart grid. Commun Mag, IEEE 2012;50:150-6.

[11] Miao H, Junshan Z. A dependency graph approach for fault detection and localization towards secure smart grid. Smart Grid, IEEE Trans 2011;2:342-51.

[12] Fouda MM et al. A lightweight message authentication scheme for smart grid communications. Smart Grid, IEEE Trans 2011;2:675-85.

[13] Young-Jin $\mathrm{K}$ et al. A secure decentralized data-centric information infrastructure for smart grid. Commun Mag, IEEE 2010;48:58-65.

[14] Rodri et al. A stationary reference frame grid synchronization system for threephase grid-connected power converters under adverse grid conditions. Power Electron, IEEE Trans 2012;27:99-112.

[15] Chouder A, Silvestre S. Automatic supervision and fault detection of PV systems based on power losses analysis. Energy Convers Manage 2010;51: 1929-37.

[16] Vijayakumar, Malathi 2017, 'An enhanced ACO and PSO based fault identification and rectification approaches for FACTS devices', International Trans Electrical Energy System, e2344..

[17] Huimin L et al. Design of smart MVDC power grid protection. Instrum Meas, IEEE Trans 2011;60:3035-46.

[18] Rongxing L et al. EPPA: an efficient and privacy-preserving aggregation scheme for secure smart grid communications. Parallel Distributed Syst, IEEE Trans 2012;23:1621-31.

[19] Calderaro V et al. Failure identification in smart grids based on petri net modeling. Ind Electron, IEEE Trans 2011;58:4613-23.

[20] Chanda D., Kishore N. K. and Sinha A. K.,"Application of wavelet multi-resolution analysis for identification and classification of faults on transmission lines", Int. Journal of Electric Power Systems Research, Vol. 73, No. 3, pp. 323- 333, 2005.

[21] Upendar J., Gupta C. P. and Singh G. K., "Discrete wavelet transform and probabilistic neural network based algorithm for classification of fault on transmission systems", India Conference INDICON 2008, pp. 206-211, 2008.

[22]Vijayakumar, Malathi, 2014, 'A real-time management and evolutionary optimization scheme for a secure and flexible smart grid towards sustainable energy', Electrical Power and Energy Systems 62 ,pp. 540 548

[23] Alonso $M$ et al. Integration of renewable energy sources in smart grids by means of evolutionary optimization algorithms. Expert Syst Appl 2012;39:5513-22. 
[24] Xu L et al. Securing smart grid: cyber attacks, countermeasures, and challenges. Commun Mag, IEEE 2012;50:38-45

[25] Jin $\mathrm{Y}$ et al. Multi-terminal DC wind farm collection grid internal fault analysis and protection design. Power Delivery, IEEE Trans 2010;25:2308-18. 